\title{
10 health stories that mattered: July 26-Aug. 1
}

- The risk posed to Canada by the Ebola virus is very low, assures Dr. Gregory Taylor, Canada's deputy chief public health officer. In a statement, Taylor said that Canada has systems to identify and prevent the spread of infectious diseases, procedures at borders to identify sick travellers and hospitals with "sophisticated infection control."

- Health Canada has asked licensed medical marijuana growers to remove inappropriate advertising from their websites and company materials, according to a memo obtained by the Ottawa Citizen. Producers are not permitted to use misleading information or specific therapeutic claims to market cannabis.

- Health Canada has earmarked $\$ 3.6$ million to develop evidencebased practices for prescribing commonly abused prescription drugs such as opioids, stimulants and sedatives. Federal Health Minister Rona Ambrose has issued a call for proposals on how to improve prescribing practices for these classes of drugs.

- Canadians foresee health and medical costs being their largest expense in their senior years, according to a report by the BMO Wealth Institute. Of the more than 1000 Canadians surveyed, $74 \%$ said medical and health costs were their primary financial con- cerns for their later years, followed by food, clothing and day-to-day essentials $(57 \%)$ and housing (56\%).

- Quebec Minister of Education, Recreation and Sports Dr. Yves Bolduc will repay $\$ 27072$ to the province and donate $\$ 28000$ to charities from the $\$ 215000$ he received in bonuses for taking on 1500 new patients during a 19-month stint in the opposition. Bolduc came under criticism for dropping those patients without follow-up upon becoming education minister. Following up with patients at least once in a 12 -month period is a requirement for collecting the premiums.

- Two Vancouver pharmacies plan to offer free HIV tests that will return results in less than five minutes. One goal of the year-long pilot project is to reduce stigma around HIV testing to encourage more people to get tested.

- All complaints about Ontario doctors that are serious enough to warrant investigation by the College of Physicians and Surgeons of Ontario should be made public, says the Ontario Trial Lawyers Association. The college currently publishes decisions by its discipline committee, but those made up only $2 \%$ of the 2294 complaints investigated last year.
- The Alberta government is close to completing a year-long study of in vitro fertilization procedures to determine if the province should fund them. Albertans currently pay \$8000-\$15000 out of pocket for a round of in vitro fertilization, depending on procedure options and drug coverage.

- The New Brunswick Medical Society wants its provincial government to make a plan to improve access to abortions. Barriers in New Brunswick include family doctors who refuse to refer women for abortions and hospitals that lack resources to perform the procedure in a timely manner.

- A New Brunswick doctor should face disciplinary measures for 350 cases of unauthorized access to the medical files of 141 women who were not his patients, recommends a report by the province's privacy commissioner. The report also recommends that the Vitalité Health Network, which employs the radio-oncologist under question (Dr. Fernando Rojas Lievano), should conduct more frequent random audits of access to electronic medical records and should quickly limit access to patient files when suspicious activity is discovered. Roger Collier, CMAJ

CMAJ 2014. DOI:10.1503/cmaj.109-4868 